\title{
Medical Radioisotopes Produced Using the Alpha Particle Beam from the Warsaw Heavy Ion Cyclotron
}

\author{
K. Szkliniarz ${ }^{b}$, J. JastrzęBski ${ }^{a, *}$, A. Bilewicz $^{c}$, E. Chajduk $^{c}$, J. Choiński $^{a}$,

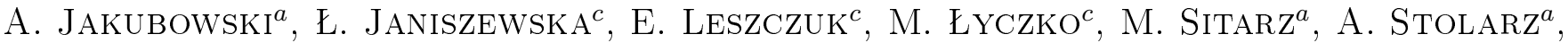 \\ A. TRZCIŃSKA ${ }^{a}, \mathrm{~B}$. WĄS ${ }^{d}$ AND W. ZIPPER ${ }^{b}$ \\ ${ }^{a}$ Heavy Ion laboratory, University of Warsaw, 02-093 Warszawa, Poland \\ ${ }^{b}$ Institute of Physics, Department of Nuclear Physics, University of Silesia, \\ Uniwersytecka 4, 40-007 Katowice, Poland \\ ${ }^{c}$ Institute of Nuclear Chemistry and Technology, 03-195 Warszawa, Poland \\ ${ }^{d}$ Niewodniczański Institute of Nuclear Physics PAS, 31-342 Kraków, Poland
}

\begin{abstract}
The internal alpha particle beam of the heavy ion cyclotron operated by the Heavy Ion Laboratory (HIL) of the University of Warsaw has a maximum energy of $32 \mathrm{MeV}$ and currently an intensity of up to $1 \mathrm{p} \mu \mathrm{A}$. This beam is used by the HIL-University of Silesia collaboration for the production of research quantities of ${ }^{211} \mathrm{At},{ }^{72} \mathrm{Se} /{ }^{72} \mathrm{As}$ and ${ }^{43,44} \mathrm{Sc}$ radioisotopes. The produced activities are transported to the Institute of Nuclear Chemistry and Technology in Warsaw where research on therapeutic and imaging radiopharmaceuticals based on these radioisotopes is pursued.
\end{abstract}

DOI: $10.12693 /$ APhysPolA.127.1471

PACS: 87.57.un, 87.57.-S

\section{Introduction}

In recent years an important part of the activity of the Heavy Ion Laboratory (HIL), a department of the University of Warsaw, has been devoted to nuclear physics applications in the life sciences, see e.g. [1-3]. In this paper we concentrate on the production of research quantities of radioisotopes with possible future uses in nuclear medicine employing the internal alpha particle beam of the U200P heavy ion cyclotron, which began operation more than twenty years ago [4]. The radioisotopes currently studied are: ${ }^{211} \mathrm{At},{ }^{72} \mathrm{Se} /{ }^{72} \mathrm{As}$ and ${ }^{44,43} \mathrm{Sc}$, produced on ${ }^{209} \mathrm{Bi}$, nat $\mathrm{GeO}_{2}$ and ${ }^{\text {nat }} \mathrm{CaO}$ targets. After the determination of their thick target production yield, expected saturation yield and radionuclidic purity the irradiated radioactive samples are transported to the Institute of Nuclear Chemistry and Technology, where the binding of these radionuclides to the various precursors and bioconjugates is performed (see e.g. [5]).

\section{Target preparation}

Targets for these studies were prepared using various techniques. The metallic Bi targets used for studying the ${ }^{209} \operatorname{Bi}(\alpha, 2 \mathrm{n})^{211}$ At reaction were produced by direct melting of grains of pure $(5 \mathrm{~N}) \mathrm{Bi}$ metal onto the target cavity in aluminium backing. The depth of the cavity corresponds to the thickness of the target. The backing, together with the Bi grains, was heated on a hot plate and the molten $\mathrm{Bi}$ was distributed over the area of the cavity with the help of a graphite spatula. Due to the

* corresponding author; e-mail: jastj@slcj.uw.edu.pl use of an internal beam the target has a special shape, i.e. one edge is frameless. Details of the Bi preparation procedure may be found in Ref. [6].

Targets for the other two reactions, i.e. ${ }^{70} \mathrm{Ge}(\alpha, 2 \mathrm{n}){ }^{72} \mathrm{Se}$ and ${ }^{40} \mathrm{Ca}(\alpha, \mathrm{p}){ }^{43} \mathrm{Sc}$, were prepared from the oxides. In both cases the appropriate amount of the relevant oxide, i.e. ${ }^{\text {nat }} \mathrm{GeO}_{2}$ or ${ }^{\text {nat }} \mathrm{CaO}$, was mixed with diluted glue and after the mixture had been distributed over the cavity of the aluminium backing it was left to dry. The shape of the cavity (one side open) does not allow the application of powder sedimentation from the diluted glue, the technique described in [7], but this modification gave targets that were stable under beam.

All targets were fixed to a copper holder, wrapped in thin aluminium foil (to retain potential vapour from the target material or pieces of it peeling off the backing) and covered with thin copper foil for beam monitoring.

\section{Targeted alpha therapy radioisotope ${ }^{211} \mathrm{At}$}

During the last few years special attention has been concentrated on alpha-particle emitters as therapeutic radioisotopes. Alpha particles, thanks to their large linear energy transfer (LET $\alpha \approx 100 \mathrm{keV} / \mu \mathrm{m}$ ) are very well suited to double-strand breaking of malignant cells. Their range in tissue is $40-100 \mu \mathrm{m}$ which corresponds to the dimension of a few cells. They are very effective in the destruction of small tumours of a few cells in dimension with much lower interaction with surrounding healthy cells, provided a vector molecule that can effectively seek out the tumour cells is identified and the link between this molecule and the alpha-particle emitter is chemically established. 


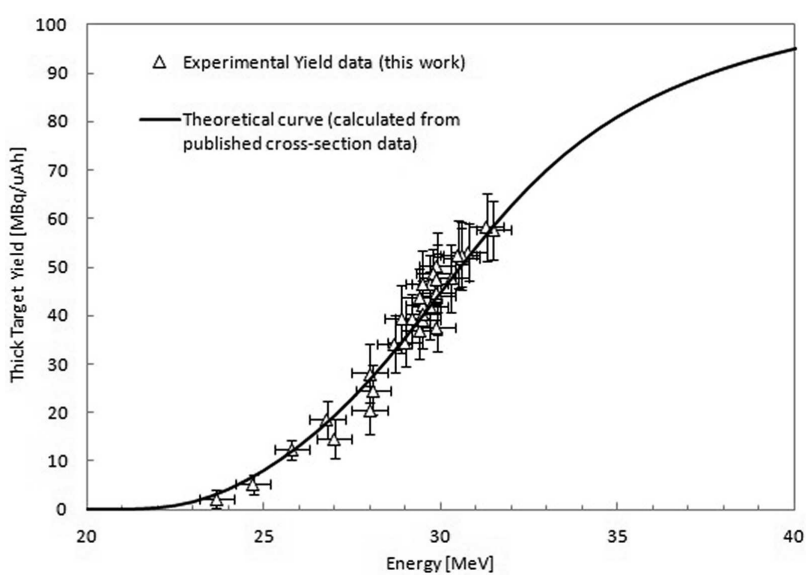

Fig. 1. Experimental thick target yield [9] for the production of ${ }^{211}$ At by $(\alpha, 2 \mathrm{n})$ reaction on Bi target. Theoretical curve was calculated using the cross-section data of Ref. [10].

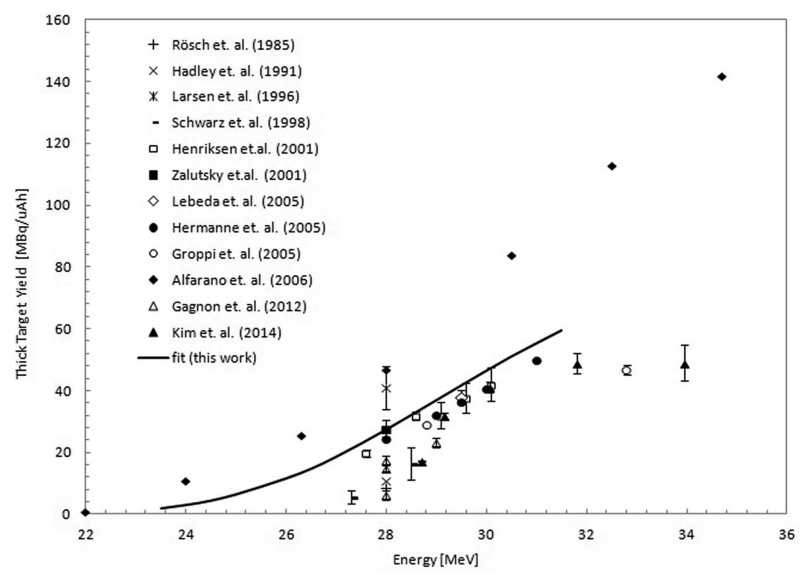

Fig. 2. Comparison of previously published thick target yield for the ${ }^{211}$ At production by the $(\alpha, 2 \mathrm{n})$ reaction with the fit to the present experimental points, as presented in Fig. 1.

TABLE

Thick target yield (TTY) and saturation yield (SY) of radioisotopes produced by $\alpha$ particle beam

\begin{tabular}{|c|c|c|c|c|c|}
\hline Isotope & $\begin{array}{c}\text { Target } \\
\text { chemical } \\
\text { form }\end{array}$ & $\begin{array}{c}\text { Target } \\
\text { thickness } \\
{\left[\mathrm{mg} / \mathrm{cm}^{2}\right]}\end{array}$ & $\begin{array}{c}\alpha \text { particle } \\
\text { energy } \\
{[\mathrm{MeV}]}\end{array}$ & $\begin{array}{c}\text { TTY } \\
{[\mathrm{MBq} / \mu \mathrm{Ah}]}\end{array}$ & $\begin{array}{c}\mathrm{SY} \\
{[\mathrm{MBq} / \mu \mathrm{A}]}\end{array}$ \\
\hline \multirow{3}{*}{$211 \mathrm{At}$} & \multirow{6}{*}{$209 \mathrm{Bi}$} & \multirow{6}{*}{98} & 29 & $37(6)$ & $394(64)$ \\
\hline & & & 30 & $46(5)$ & $495(53)$ \\
\hline & & & 31 & $55(7)$ & $591(74)$ \\
\hline \multirow{3}{*}{$210 \mathrm{At}$} & & & 29 & $0.009(2)$ & $0.10(2)$ \\
\hline & & & 30 & $0.06(1)$ & $0.8(1)$ \\
\hline & & & 31 & $0.5(1)$ & $6(1)$ \\
\hline $72 \mathrm{Se}$ & \multirow{2}{*}{${ }^{\text {nat }} \mathrm{GeO}_{2}$} & \multirow[b]{2}{*}{125} & \multirow[b]{2}{*}{30.5} & $0.26(3)$ & $76(7)$ \\
\hline $72 \mathrm{As}$ & & & & $2.8(1)$ & $105(5)$ \\
\hline $43 \mathrm{Sc}$ & \multirow{3}{*}{${ }^{\text {nat }} \mathrm{CaO}$} & \multirow{3}{*}{98} & \multirow{3}{*}{31} & $98(10)$ & $547(55)$ \\
\hline $44 \mathrm{Sc}$ & & & & $0.66(3)$ & $3.7(5)$ \\
\hline $44 \mathrm{mSc}$ & & & & $0.042(4)$ & $3.6(3)$ \\
\hline
\end{tabular}

The ${ }^{211}$ At isotope is one of the most promising alpha emitters that could be applied to radionuclide targeted therapy. However, until now its links to a vector molecule are still in the research phase, although some preclinical studies have already been published. Our recent results $[5,8]$ indicate that we are close to a solution for finding a relatively stable radiopharmaceutical which can at least be employed externally for glioma cancer treatment.

Production of ${ }^{211}$ At was started in 2010 and is continuing. In Fig. 1 the thick target production yield [9] of this isotope, as determined in this work from the crosssection data [10] via the investigation of its gamma ray spectrum [11], is shown. Figure 2 compares the results of the present work with the available data from the literature. Finally, Table shows the determined thick target production yield and saturation yield for three bombarding energies. It is worth mentioning here that producing ${ }^{211}$ At by the $(\alpha, 2 n)$ reaction one should avoid the formation of the very dangerous ${ }^{210} \mathrm{At}$ isotope. Therefore, in Table the yield of this isotope produced by the $(\alpha, 3 \mathrm{n})$ reaction above $29 \mathrm{MeV}$ bombarding energy is also shown. The activity ratio of these two isotopes was used for the exact energy determination of the $\mathrm{He}+$ beam. The lower energy points in Fig. 1 were obtained using Al beam energy degraders.

\section{Positron emitting generator pair ${ }^{72} \mathrm{Se} /{ }^{72} \mathrm{As}$}

The ${ }^{72} \mathrm{Se} /{ }^{72} \mathrm{As}$ pair is listed in Ref. [12] between rather long-lived generator pairs where the daughter nucleus, although also emitting a number of gamma rays, has potential for positron emission tomography techniques in places where no cyclotron is available and/or rather long physiological processes are to be investigated. (The considered pair have half-lives of $8.5 \mathrm{~d}$ and $26 \mathrm{~h}$, respectively.) ${ }^{72}$ Se may be produced by the $(\mathrm{p}, 4 \mathrm{n})$ reaction on a mono-isotopic ${ }^{75}$ As target or the $(\alpha, 2 \mathrm{n})$ reaction on a $21 \%{ }^{70} \mathrm{Ge}$ target. Although the calculated crosssection for this reaction extends up to $50 \mathrm{MeV}$ the reaction threshold is at $18 \mathrm{MeV}$, and it may be expected that the use of a $30 \mathrm{MeV}$ alpha particle beam (from e.g. a C30XP cyclotron) may still produce a sufficient quantity of the mother radioisotope to be applied to the production of this generator.

The investigation of the thick target production yield of this reaction was also motivated by a chemical study of the ${ }^{72}$ Se extraction efficiency and purity from a ${ }^{\text {nat }} \mathrm{GeO}_{2}$ target, irradiated with a $30 \mathrm{MeV}$ alpha particle beam [13]. In addition to the $(\alpha, 2 \mathrm{n})$ reaction producing ${ }^{72} \mathrm{Se}$ a rather similar cross-section was calculated using the EMPIRE code [14] for the production of ${ }^{72} \mathrm{As}$ via the $(\alpha, \mathrm{pn})$ reaction. The thick target production yields and saturation yields of these reactions determined in this study are presented in Table. The chemical investigation [13] also indicated a rather pure ${ }^{72} \mathrm{As}$ extraction from the produced ${ }^{72}$ Se activity.

A simple calculation indicates that if the irradiation time with this alpha particle energy were $8 \mathrm{~h}$ and the beam intensity $40 \mu \mathrm{A}$ a $60 \mathrm{MBq}$ EOB (end of 
beam) Se generator could be produced. Again, assuming $100 \%$ chemical extraction efficiency, 3 days after EOB a $50 \mathrm{MBq}$ and 15 days after EOB a $20 \mathrm{MBq}$ As activity could be extracted.

\section{Positron emitting ${ }^{43,44}$ Sc radioisotopes}

These two emerging radioisotopes of a similar half-life $(4 \mathrm{~h})$ are expected to replace in some cases the shorter lived ${ }^{18} \mathrm{~F}$ or to be a substitute for ${ }^{68} \mathrm{Ga}$ for some special tumours, insensitive to fluorine compounds. ${ }^{44} \mathrm{Sc}$ is an ideal radioisotope for three photon techniques [15], where a rather high energy gamma transition is used to substantially increase the resolution of the PET image, smeared out due to the positron range.

There is a number of nuclear reactions which lead to the formation of these radionuclides using medical $\mathrm{p} / \mathrm{d}$ cyclotrons and isotopically separated targets. In the present study an alternative way [16] was investigated by irradiating a natural $\mathrm{CaO}$ target $\left(97 \%{ }^{40} \mathrm{Ca}\right)$ with the alpha particle beam. This investigation was only initiated and will be continued during the following months. The calculated [14] $(\alpha, \mathrm{p})$ reaction on a ${ }^{40} \mathrm{Ca}$ target has a threshold at $5 \mathrm{MeV}$, a maximum cross-section of about $840 \mathrm{mb}$ at $14 \mathrm{MeV}$ and decreases to $340 \mathrm{mb}$ above $20 \mathrm{MeV}$. (The maximal calculated cross-section of $(\alpha, \mathrm{n})$ reaction is only $40 \mathrm{mb}$ and has its maximum at roughly the same bombarding energy.) Therefore, a rather pure ${ }^{43} \mathrm{Sc}$ activity would be produced using an alpha particle energy below $20 \mathrm{MeV}$. However, $30 \mathrm{MeV}$ bombarding energy was instead used for the first irradiations, in order to estimate also the ${ }^{44} \mathrm{Sc}$ production rate on a ${ }^{42} \mathrm{Ca}$ target $(0.6 \%$ in natural $\mathrm{Ca})$ using the $(\alpha, \mathrm{pn})$ reaction. The determined thick target yields and saturation yields for the ${ }^{43} \mathrm{Sc}$ and ${ }^{44} \mathrm{Sc}$ radioisotopes are shown in Table. Figure 3 shows the radionuclidic purity of ${ }^{43} \mathrm{Sc}$ as a function of time after the EOB.

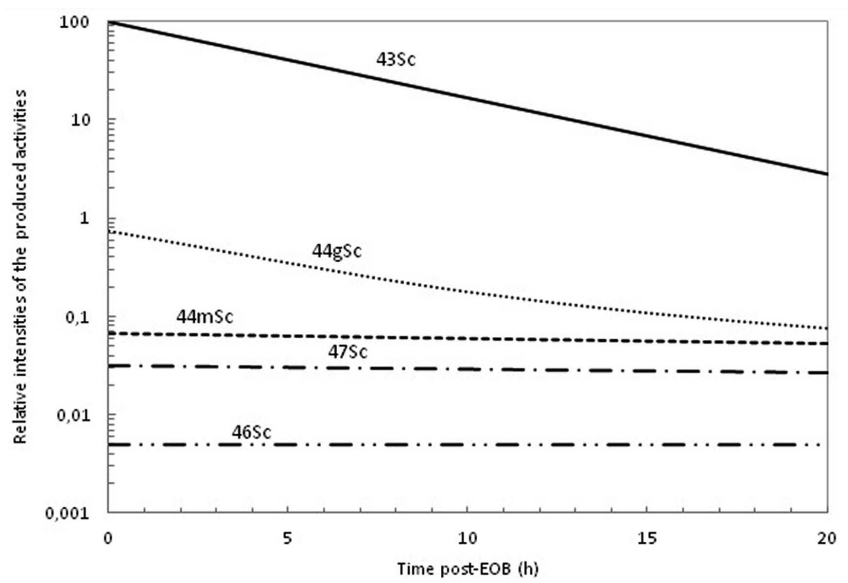

Fig. 3. Evolution in time of the relative intensities of $\mathrm{Sc}$ isotopes produced during a $4 \mathrm{~h}$ irradiation of the ${ }^{\text {nat }} \mathrm{CaO}$ target with $31 \mathrm{MeV} \alpha$ particle beam.

\section{6. ${ }^{211}$ At radiopharmaceuticals}

Bismuth targets irradiated at HIL were transported to the Institute of Nuclear Chemistry and Technology where ${ }^{211}$ At was isolated from the target by thermochromatographic methods. Our studies with ${ }^{211}$ At have been directed to obtaining a radiopharmaceutical for the treatment of the residue of glioma cancer cells after brain tumour resection. For the binding of ${ }^{211}$ At to substance $P$ (a vector with high affinity to the NK1 receptor on glioma cells) the following approaches were studied: attaching ${ }^{211}$ At to $\mathrm{Rh}^{3+}$ tetrathioether complexes such as $\mathrm{Rh}\left[16 \mathrm{aneS}_{4}\right.$-diol] ${ }^{211}$ At $[17,8]$, the adsorption of ${ }^{211}$ At on silver impregnated $\mathrm{TiO}_{2}$ nanoparticles [5] and recently adsorption on gold nanoclusters and nanoparticles [18]. The radiobioconjugates obtained exhibited good stability in various biological liquids including human serum and cerebral spinal fluid. In the short term studies on cell affinity and radiotoxicity of the obtained radiobioconjugates will be performed.

\section{Conclusions}

The heavy ion cyclotron operating at the Heavy Ion Laboratory of the University of Warsaw has been extensively employed in recent years for the production of medical radioisotopes using the internal $\mathrm{He}+$ beam. The maximum energy of this beam is $32 \mathrm{MeV}$ and currently the intensity is of up to $1 \mathrm{p} \mu \mathrm{A}$. Although this intensity is sufficient for the production of research quantities of these radioisotopes, a more intense beam would be needed for their production for clinical applications. An upgrade of the HIL cyclotron and the installation in the Warsaw area of a new machine accelerating alpha particles are being considered.

\section{Acknowledgments}

The authors warmly thank the HIL cyclotron operation team for running a number of the beam hours necessary for the research described in this paper and express their thanks to the students from the University of Silesia for their help during the course of the diploma and master's studies at the Heavy Ion Laboratory in Warsaw. Discussions with Ulli Koester are also appreciated. One of the authors (K.S.) is supported through an Doktoris project co-financed by EU from the European Social Fund.

\section{References}

[1] J. Jastrzębski, Acta Phys. Pol. B 43, 193 (2012).

[2] J. Choiński, J. Jastrzębski, K. Kilian, I. Mazur, P.J. Napiorkowski, A. Pękal, D. Szczepaniak, EPJ Web of Conferences 66, 10003 (2014).

[3] J. Czub, D. Banaś, A. Błaszczyk, J. Braziewicz, I. Buraczewska, J. Choiński, U. Górak, M. Jaskóła, A. Korman, A. Lankoff, H. Lisowska, A. Łukaszek, Z. Szefliński, A. Wójcik Appl. Radiat. Isot. 67, 447 (2009).

[4] J. Choiński, T. Czosnyka, J. Dworski, J. Jastrzębski, J. Kownacki, E. Kulczycka, J. Kurzyński, J. Miszczak, A. Stolarz, K. Sudlitz, J. Sura, L. Zemło, Nukleonika 48, S109 (2003). 
[5] E. Leszczuk, M. Łyczko, A. Piotrowska, A. Bilewicz, A. Stolarz, A. Trzcińska, K. Szkliniarz, B. Wąs, $R a$ diochim. Acta, in press.

[6] J. Choiński, A. Jakubowski, J. Jastrzębski, B. Paprzycki, A. Pietrzak, R. Tańczyk, A. Stolarz, D. Szczepaniak, A. Trzcińska, J. Chudyka, K. Tworek, W. Zipper, B. Petelenz, B. Was, A. Bilewicz, M. Łyczko, HIL Annual Report 2011, Eds. M. Palacz, N. Keeley, University of Warsaw, Warsaw 2012, p. 52.

[7] A. Stolarz, Nucl. Instrum. Methods Phys. Res. A 397, 114 (1997).

[8] M. Łyczko et al., in preparation.

[9] N.N. Krasnov, Int. J. Appl. Radiat. Isot. 25, 223 (1974).

[10] IAEA, Nuclear Data for the Production of Therapeutic Radionuclides, Vienna 2010.
[11] National Nuclear Data

Center

(http://www.nndc.bnl.gov/), 2013.

[12] IAEA, Radioisotopes and Radiopharmaceuticals Series No. 2, Vienna 2010.

[13] E. Chajduk et al., to be published.

[14] M. Herman, R. Capote, B.V. Carlson, P. Obložinský, M. Sin, A. Trkov, H. Wienke, V. Zerkin, NDS 108, 2655 (2007).

[15] P. Thirolf, Acta Phys. Pol. A 127, 1441 (2015).

[16] S. Krajewski, A. Majkowska-Pilip, A. Bilewicz, private communication.

[17] M. Pruszyński, A. Bilewicz, M.R. Zalutsky, Bioconjugate Chem. 19, 958 (2008).

[18] Ł. Janiszewska et al., to be published. 